\title{
Suppression of canonical Wnt/3-catenin signaling by nuclear plakoglobin recapitulates phenotype of arrhythmogenic right ventricular cardiomyopathy
}

\author{
Eduardo Garcia-Gras,1 Raffaella Lombardi, ${ }^{1}$ Michael J. Giocondo,, James T. Willerson, ${ }^{2}$ \\ Michael D. Schneider, ${ }^{1}$ Dirar S. Khoury, ${ }^{1}$ and Ali J. Marian ${ }^{1}$
}

\author{
${ }^{1}$ Section of Cardiology and Center for Cardiac Development, Department of Medicine, Baylor College of Medicine, Houston, Texas, USA. \\ 2University of Texas Health Science Center at Houston, Houston, Texas, USA.
}

\begin{abstract}
Arrhythmogenic right ventricular dysplasia/cardiomyopathy (ARVC) is a genetic disease caused by mutations in desmosomal proteins. The phenotypic hallmark of ARVC is fibroadipocytic replacement of cardiac myocytes, which is a unique phenotype with a yet-to-be-defined molecular mechanism. We established atrial myocyte cell lines expressing siRNA against desmoplakin (DP), responsible for human ARVC. We show suppression of DP expression leads to nuclear localization of the desmosomal protein plakoglobin and a 2-fold reduction in canonical Wnt/ $\beta$-catenin signaling through Tcf/Lef1 transcription factors. The ensuing phenotype is increased expression of adipogenic and fibrogenic genes and accumulation of fat droplets. We further show that cardiac-restricted deletion of $D s p$, encoding DP, impairs cardiac morphogenesis and leads to high embryonic lethality in the homozygous state. Heterozygous DP-deficient mice exhibited excess adipocytes and fibrosis in the myocardium, increased myocyte apoptosis, cardiac dysfunction, and ventricular arrhythmias, thus recapitulating the phenotype of human ARVC. We believe our results provide for a novel molecular mechanism for the pathogenesis of ARVC and establish cardiac-restricted DP-deficient mice as a model for human ARVC. These findings could provide for the opportunity to identify new diagnostic markers and therapeutic targets in patients with ARVC.
\end{abstract}

\section{Introduction}

Cardiomyopathies are primary cardiac myocyte disorders with a diverse array of phenotypic expression that encompass heart failure and sudden cardiac death (SCD). Arrhythmogenic right ventricular dysplasia/cardiomyopathy (ARVC) is an uncommon cardiomyopathy with distinct pathological and clinical features $(1,2)$. The characteristic pathological hallmark of ARVC is fibroadipocytic replacement of cardiac myocytes that typically occurs in conjunction with myocyte apoptosis and cardiac dysfunction (1, 2). Clinically, ARVC is responsible for approximately $5 \%$ of unexplained SCD cases in young athletes in the United States and up to $27 \%$ of such cases in Italy $(1,3,4)$. Cardiac dysfunction is common and often initiates from the right ventricle but is usually global in advanced stages of the disease (1). In a subset of the cases, the left ventricle is the predominant site of involvement $(5,6)$.

ARVC is a familial disease, with a Mendelian pattern of inheritance in approximately one-third to one-half of the cases (2). The mode of inheritance is typically autosomal-dominant with variable penetrance. However, autosomal-recessive forms also have been described that occur in conjunction with hair and skin disorders and are referred to as cardiocutaneous syndromes (2).

Nonstandard abbreviations used: ARVC, arrhythmogenic right ventricular dysplasia/cardiomyopathy; C/EBP- $\alpha$, CCAAT enhancer-binding protein- $\alpha$; CPTV, catecholaminergic polymorphic ventricular tachycardia; DP, desmoplakin; $\alpha$-MHC, $\alpha$-myosin heavy chain; PG, plakoglobin; PKP2, plakophilin 2; SCD, sudden cardiac death; Tcf/ Lef, T cell/lymphoid-enhancing binding.

Conflict of interest: The authors have declared that no conflict of interest exists. Citation for this article: J. Clin. Invest. 116:2012-2021 (2006). doi:10.1172/JCI27751.
Naxos disease is a syndrome of autosomal-recessive ARVC, nonepidermolytic palmoplantar keratoderma, and woolly hair, which was described in families from the island of Naxos in Greece (7). Another form of cardiocutaneous syndrome, referred to as Carvajal syndrome, is characterized by dilated cardiomyopathy predominantly involving the left ventricle $(5,6)$.

The genetic basis of ARVC is partially known. Several loci have been mapped, and 4 causal genes encoding desmosomal proteins desmoplakin (DP), plakoglobin (PG), plakophilin 2 (PKP2) and desmoglein 2 have been identified (reviewed in ref. 2; ref. 8). Thus ARVC in a subset of families is considered a disease of desmosomal proteins.

The molecular pathogenesis of ARVC - particularly the basis for adipocytic replacement of cardiac myocytes, the hallmark of ARVC - is completely unknown $(1,2)$. Desmosomes are complex intercellular junctions assembled through cooperative interactions among multiple proteins. Desmosomal protein PG is a member of the armadillo repeat proteins with a well-established role in regulation of gene expression (9, 9-12). PG, also known as $\gamma$-catenin, has structural and functional similarities to $\beta$-catenin, which is the effector for canonical Wht signaling (13). PG is known to interact and compete with $\beta$-catenin at multiple cellular levels with a net negative effect on the canonical Wnt/ $\beta$-catenin signaling pathway through $\mathrm{T}$ cell/lymphoid-enhancing binding (Tcf/Lef) transcription factors (9-12). Accordingly, we hypothesized that mutating desmosomal protein by impairing desmosome assembly could free PG from the desmosomes, which could translocate into the nucleus and through competition with $\beta$-catenin suppress signaling through the canonical Wnt/ $\beta$-catenin-Tcf/Lef pathway. 
A

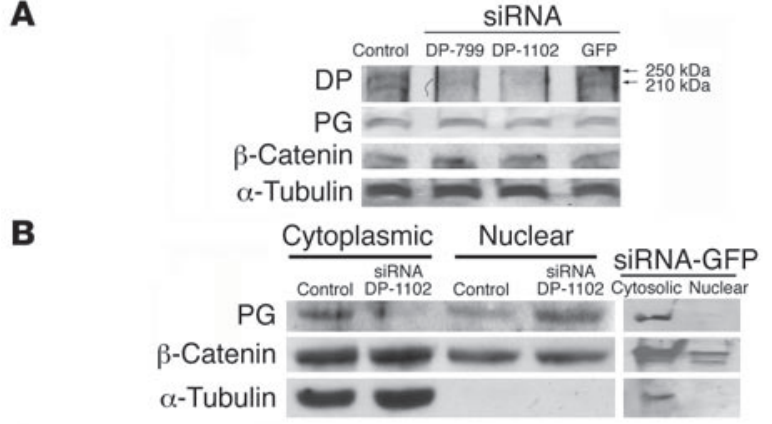

C
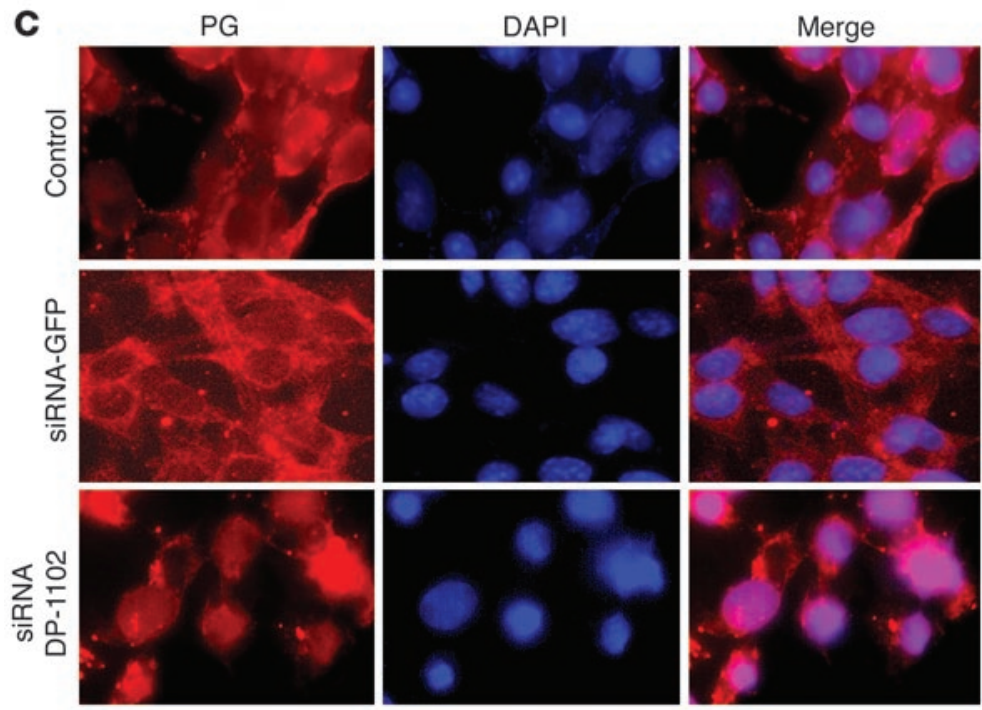

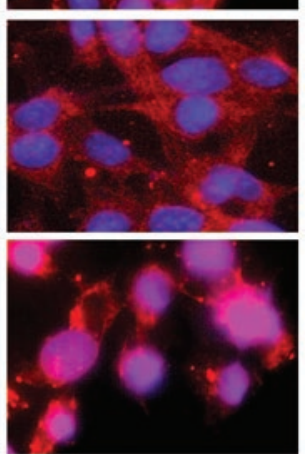

\section{Figure 1}

Suppression of DP expression in $\mathrm{HL}-1$ cells and nuclear localization of PG. (A) Immunoblots showing expression levels of DP, PG, $\beta$-catenin, and $\alpha$-tubulin - the latter as a control for loading conditions - in control cells, cells stably transfected with siRNAs against DP, and cells transfected with siRNA against GFP. (B) Immunoblots of subcellular protein extracts probed with an anti-PG antibody. PG was predominantly localized to cytoplasmic protein extracts in control HL-1 cells or cells transfected with siRNA against GFP. In contrast, PG was localized predominantly in the nuclear subfractions in DP-deficient HL-1 cells. (C) Immunofluorescence detection of PG in the nuclei. Shown are cells stained with an anti-PG antibody (left panels), nuclei stained with DAPI (middle panels), and the overlay (right panels) in nontransfected control cells (top panels), cells transfected with siRNA against GFP (middle panels), and DP-deficient HL-1 cells (bottom panels). Magnification, $\times 400$.
Suppression of Wnt $/ \beta$-catenin signaling provokes adipogenesis, fibrogenesis, and apoptosis (14-16), the characteristic hallmark of human ARVC. We tested the hypothesis initially in cultured atrial myocyte (HL-1) cell lines using sequence-specific siRNA targeted to $D s p$ and subsequently in cardiac-restricted DP-deficient mice generated using the Cre-LoxP system. Suppression of expression of DP led to nuclear localization of PG, reduced canonical Wnt signaling, enhanced myocyte apoptosis, excess fibrogenesis and adipogenesis, myocardial dysfunction, and ventricular tachycardia. The results establish what we believe to be a novel molecular mechanism for the pathogenesis of ARVC and a mouse model that recapitulates the phenotype of human ARVC.

\section{Results}

Suppression of DP expression in HL-1 cells through stable transfection using sequence-specific siRNA. Stable transfection of cultured HL-1 cells with pSilence 2.1-U6 neo plasmid expressing siRNA DP-799 or siRNA DP-1102 (the numbering refers to the position of the first nucleotide of each siRNA in Dsp mRNA) led to near total suppression of DP isoform expression compared with control nontransfected cells or HL-1 cells transfected with siRNA against GFP (Figure 1A). There were no significant changes in the expression levels of PG, $\beta$-catenin, or $\alpha$-tubulin. The HL- 1 cells transfected with siRNA DP-799 had a slower doubling time, as compared with nontransfected control cells $(33.4 \pm 3.5$ h versus $21.6 \pm 1.7 \mathrm{~h}$, respectively; $P=0.001)$ and a lower number of proliferating cell nuclear antigen-positive cells $(16.8 \pm 2.6 \%$ in siRNA DP-799 transfected cells versus $25.7 \pm 1.1 \%$ in nontransfected control cells; $P<0.01$ ).
Similarly, TUNEL-positive cells comprised $0.79 \% \pm 0.56 \%$ of the DP-deficient cells as opposed to $1.42 \% \pm 0.97 \%$ of the control DP-competent cells $(P=0.191)$. There was no discernible DNA laddering in any of the experimental groups. In addition, expression levels of the $19 \mathrm{kDa}$ fragment of caspase 3 protein were not significantly different among the experimental groups (Supplemental Figure 1; supplemental material available online with this article; doi:10.1172/JCI27751DS1).

Nuclear localization of PG in DP-deficient HL-1 cells. To determine subcellular compartmentalization of PG in DP-deficient HL cells, two complimentary methods of immunoblotting on subcellular protein fractions and immunofluorescence were performed. The results of immunoblotting were notable for the predominant localization of PG to the cytoplasmic protein fraction in the control HL-1 cells or cells transfected with siRNA against GFP (Figure 1B). In contrast, PG was predominantly localized to the nuclear protein fraction in DP-deficient cells. Immunofluorescence staining also localized PG predominantly to nuclei in DP-deficient cells, in contrast to the cytoplasmic localization in DP-competent cells (Figure 1C).

Suppression of canonical Wnt/ $\beta$-catenin signaling through Tcf/Lef1 transcription factors in DP-deficient HL-1 cells. Tcf-mediated gene transcription, as determined by the corrected ratio of pTOP-flash/pFOP-flash luciferase activity was increased approximately 16-fold in control HL-1 cells and cells transfected with siRNA against GFP. In contrast, the ratio was increased by 7 -fold in HL-1 cells stably transfected with siRNAs against DP (Figure 2), indicating a 2 -fold reduction in signaling through the canonical Wnt/ $\beta$-catenin-Tcf/Lef pathway. 


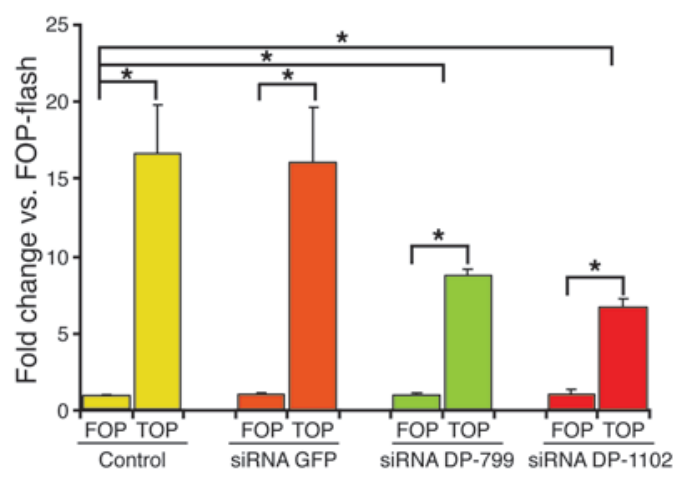

Transcriptional switch to adipogenesis and fibrogenesis in DP-deficient $H L-1$ cells. To determine whether nuclear localization of PG and suppression of canonical Wnt/ $\beta$-catenin signaling provokes adipogenesis in transfected HL-1 cells, expression levels of mRNAs of selected transcriptional regulators of adipogenesis and their target genes were determined by semiquantitative RT-PCR. The results were notable for a marked increase in expression levels of 2 major regulators of adipogenesis, namely PPAR $\gamma$ and CCAAT

\section{Figure 2}

TOP-flash assay. The relative luciferase activity in cells transfected with FOP-flash and TOP-flash vectors in controls cells, cells transfected with siRNA against GFP, and cells transfected with siRNAs against DP are shown. ${ }^{*} P<0.01$; Tukey's test.

enhancer-binding protein- $\alpha(\mathrm{C} / \mathrm{EBP}-\alpha)$ and their target genes adiponectin and lipoprotein lipase (Figure 3A). Furthermore, immunofluorescence staining with an anti-PPAR $\gamma$ antibody confirmed increased expression and nuclear localization of PPAR $\gamma$ in DP-deficient HL-1 cells (Figure 3C).

Because fibrosis is a major histological phenotype of ARVC, we determined expression levels of procollagen genes in DP-deficient HL-1 cells. The results showed a remarkable increase in expression levels of procollagen genes Col1a2, Col1a1, and Col3a1 in DP-deficient cells (Figure 3B). Finally, we determined expression levels of selected $\beta$-catenin target genes, namely cyclin D1 and c-myc, which showed modest decreases in DP-deficient cells (Figure 3D).

Accumulation offat droplets in DP-deficient HL-1 cells. To determine whether the observed transcriptional switch to fibrogenesis and adipogenesis in DP-deficient HL-1 cells was associated with

\section{Figure 3}

Transcriptional switch to adipogenesis and fibrosis and fat droplet accumulation in DP-deficient cells. (A) Semiquantitative RT-PCR results for C/EBP- $\alpha$, PPAR $\gamma$, adiponectin, lipoprotein lipase, and GAPDH, the latter as a control. In addition to control cells and cells transfected with siRNAs, RNA extracts from human heart and adipose tissue are also included. (B) Expression of procollagen genes Col1a1, Col1a2, and Col3a1 in the experimental groups. (C) Immunofluorescence staining of DP-competent and -deficient cells with an anti-PPAR $\gamma$ antibody, showing expression and nuclear localization of PPAR $\gamma$ in DP-deficient cells. (D) Expression levels of mRNAs for selected genes involved in ARVC, including Wnt signaling targets. (E) Accumulation of fat droplets in DPdeficient HL-1 cells treated with dexamethasone, insulin, and 3-isobutyl-1methylxanthine (Dex + Ins + IBMX). Magnification, $\times 400$.

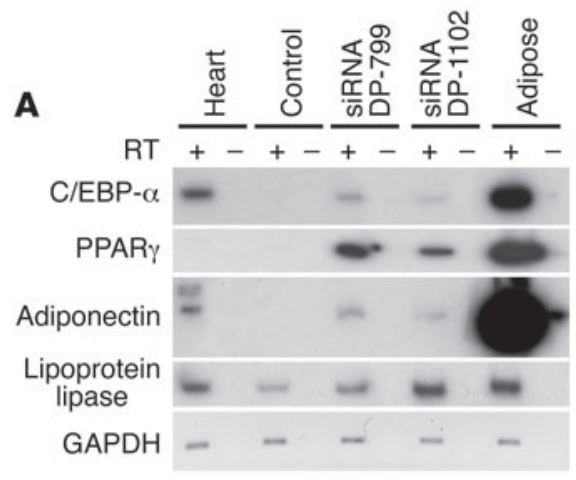

B
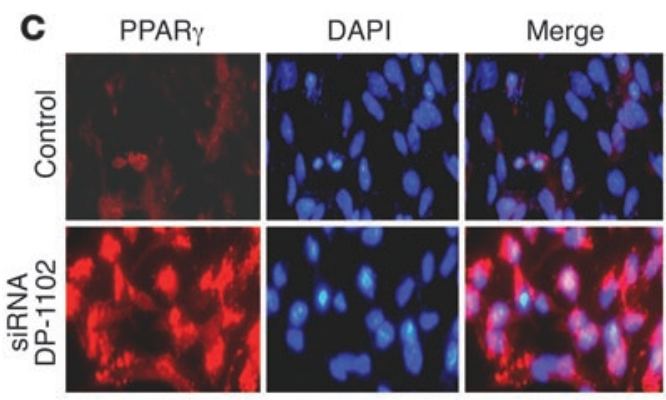

D

E

$\mathrm{Dex}+\operatorname{lns}+\mathrm{IBMX}$
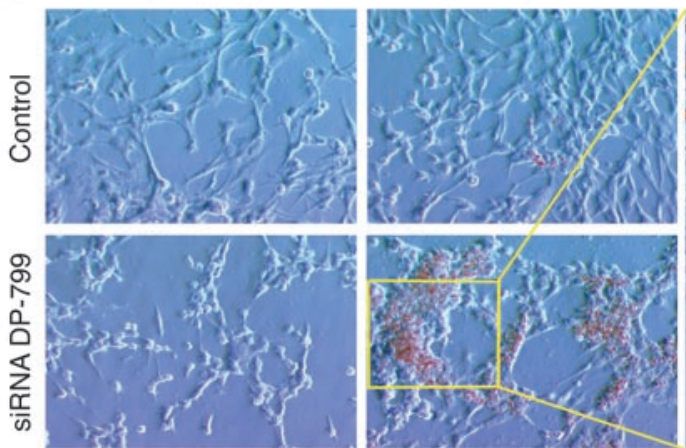
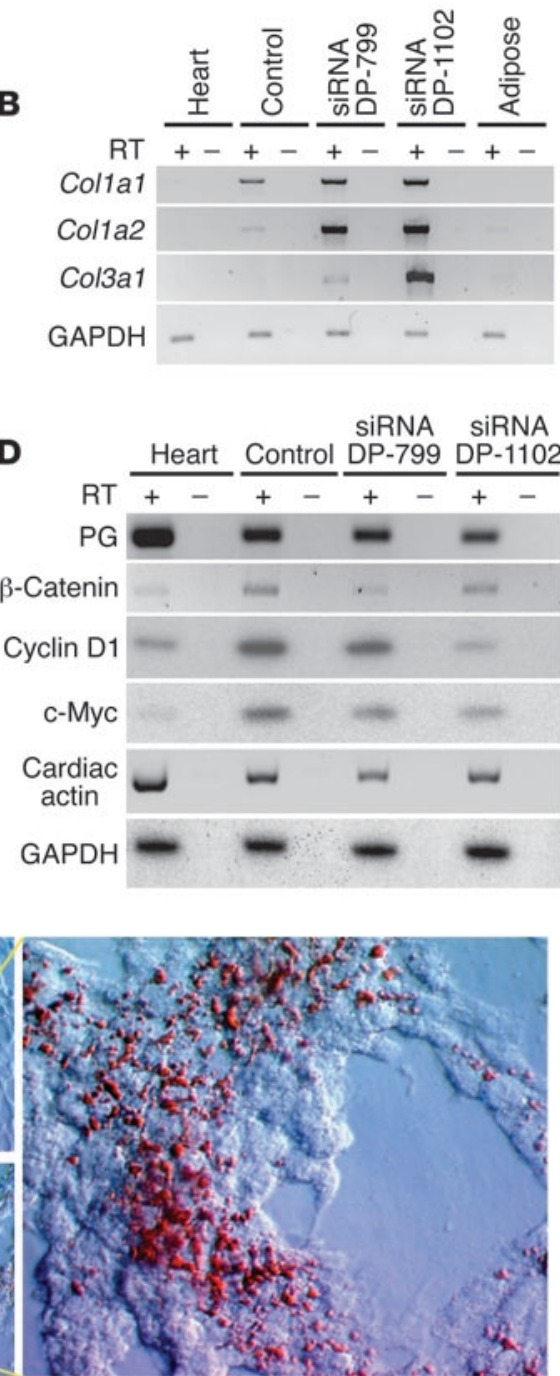

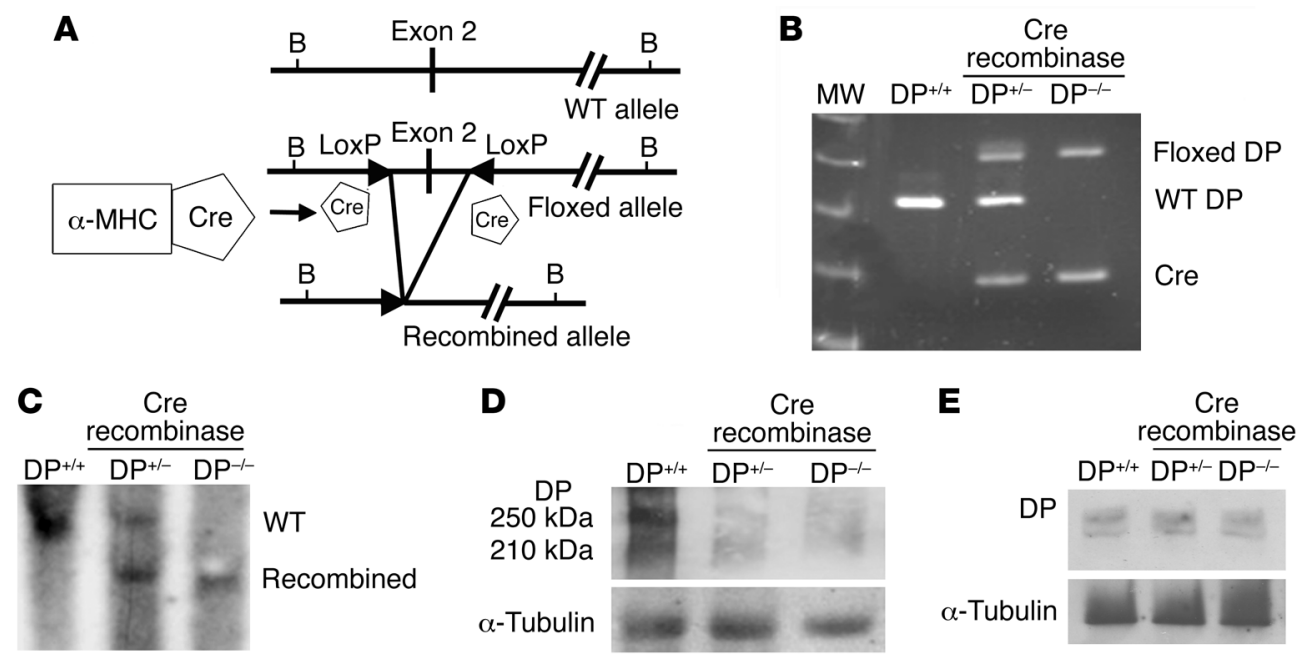

\section{Figure 4}

Targeting vector, genotyping, and detection of expression of DP. (A) The WT and floxed alleles of Dsp, location of LoxP sequences, sites of $\mathrm{BamH1}$ restriction endonuclease, and location of the probes used in Southern blotting are shown. The construct expressing Cre recombinase under the regulatory control of $\alpha-\mathrm{MHC}$ promoter is shown to the left of the panel. (B) Screening of mouse tail DNA by PCR for the presence of floxed and WT alleles and the Cre recombinase transgene in 3 experimental groups. (C) Detection of excised exon 2 and WT alleles by Southern blotting in DNA extracted from the hearts of mice in the experimental groups. (D) Immunoblots on cardiac protein extracts illustrate reduced expression of DP protein in heterozygous mice and its near complete absence in homozygous mice. $\alpha$-Tubulin was used as a control for loading conditions. (E) Equal expression levels of DP were found in skin tissues from WT, heterozygous, and homozygous DP-deficient mice.

accumulation of fat droplets, DP-deficient and -competent HL-1 cells were treated with insulin, 3-isobutyl-1-methylxanthine, and dexamethasone for 3 days and then stained with Oil Red O. The results showed a remarkable increase in accumulated fat droplets in DP-deficient HL-1 cells compared with control DP-competent cells (Figure 3E).

Screening for cardiac-restricted DP-deficient mice. The design of the targeting vector is shown in Figure 4A. Progeny of crosses between the $\alpha$-myosin heavy chain-Cre $(\alpha-\mathrm{MHC}-\mathrm{Cre})$ recombinase transgenic mice and floxed $D s p$ mice were screened by PCR to detect the presence of the transgenes in genomic DNA extracted from tails (Figure 4B). The floxed alleles were identified by the presence of a 410-bp band, as opposed to a 320-bp band for the WT allele. Cardiac-restricted excision of floxed Dsp alleles was detected by Southern blotting of DNA extracted from the myocardium using a 389-bp PCR-amplified probe (Figure 4C). Deletion of exon 2 led to a 5.3-kbp fragment, as opposed

\section{Figure 5}

Nuclear localization of PG and transcriptional switch to adipogenesis in DP-deficient mice. (A) Immunoblots of subcellular protein extracts from WT and DP-deficient mice probed with an anti-PG antibody. PG was predominantly localized to the nuclear protein subfraction in the DP-deficient mice in contrast to WT, which showed predominant localization in cytoplasmic protein subfraction. The difference between cytoplasmic and nuclear PG expression levels in $\mathrm{DP}^{+/-}$mice with $\alpha-\mathrm{MHC}-\mathrm{Cre}$ mice suggests preferential localization of free (unincorporated) PG to the nucleus. Degradation of the cytoplasmic PG by proteasomes could also contribute to lower levels PG in the cytoplasm. $\alpha$-Tubulin was used as a control for loading conditions. (B) Detection of expression levels of c-myc and cyclin D1, as target genes for canonical Wnt signaling, and C/EBP- $\alpha$ and adiponectin, as markers of adipogenesis, in WT and DP-deficient mice. Expression levels of c-myc and cyclin D1 were reduced, whereas expression levels of $\mathrm{C} / \mathrm{EBP}-\alpha$ and adiponectin were increased, in DP-deficient mice compared with WT mice. to $5.8 \mathrm{kbp}$ for the WT allele. Efficiency of the Cre recombinase in suppression of expression of DP protein was determined by immunoblotting using a polyclonal rabbit anti-DP antibody. A representative blot is shown in Figure 4D. To detect specificity of conditional deletion of Dsp in the heart, expression levels of DP were determined in skin tissues, a major site of expression of DP, by immunoblotting using an anti-DP antibody. The results showed equal expression levels of DP in WT and heterozygous ( $\left.\mathrm{DP}^{+/-}\right)$and homozygous ( $\mathrm{DP}^{-/-}$) floxed $D s p$ plus Cre recombinase transgenic mice (Figure 4E).

High lethality in $\mathrm{DP}^{-/-}$embryos. The number of newborn mice with cardiac-restricted $\mathrm{DP}^{-/-}\left(\mathrm{DP}^{-/-}\right.$plus $\alpha$-MHC-Cre) was significantly lower than the expected number per Mendelian inheri-

A

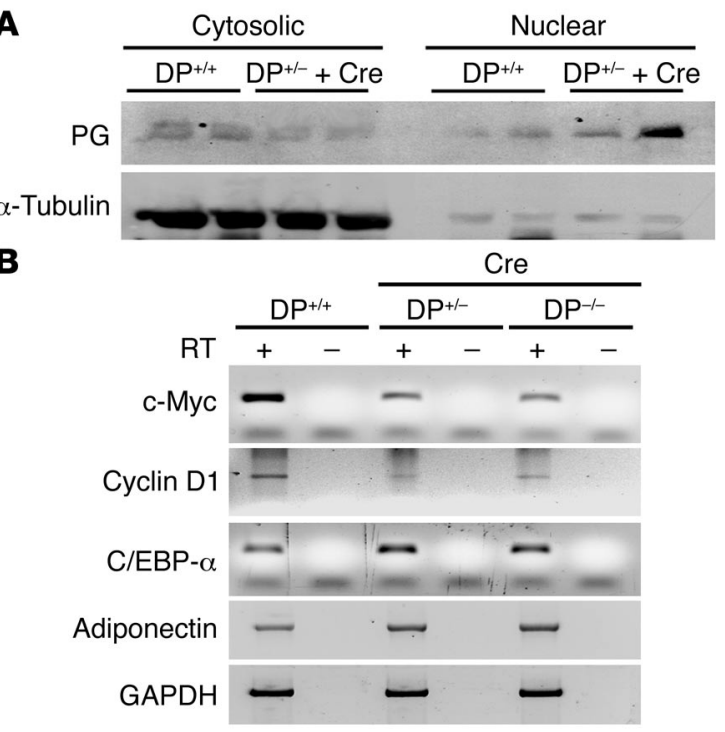


A

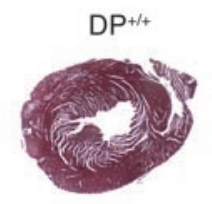

B

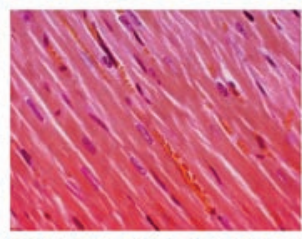

C

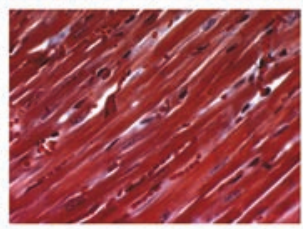

D

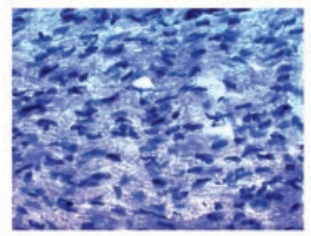

E

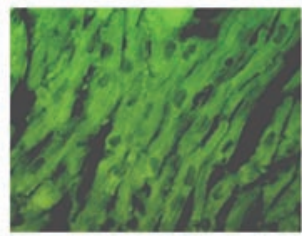

$\mathbf{F}$

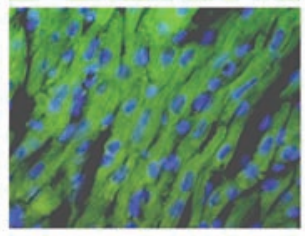

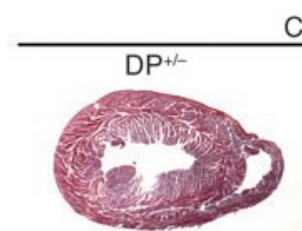

Cre
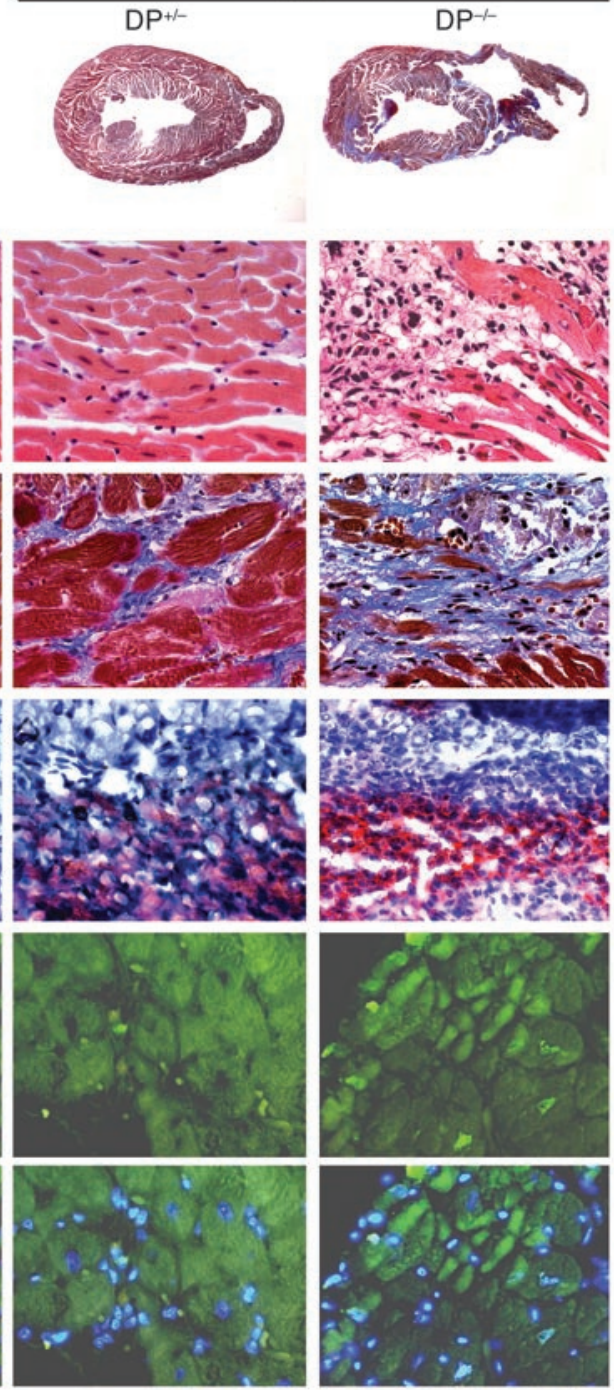
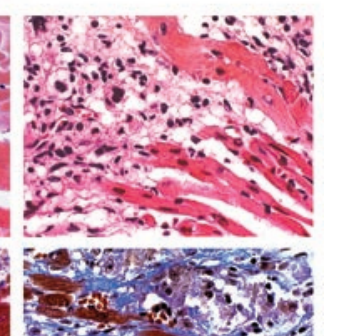
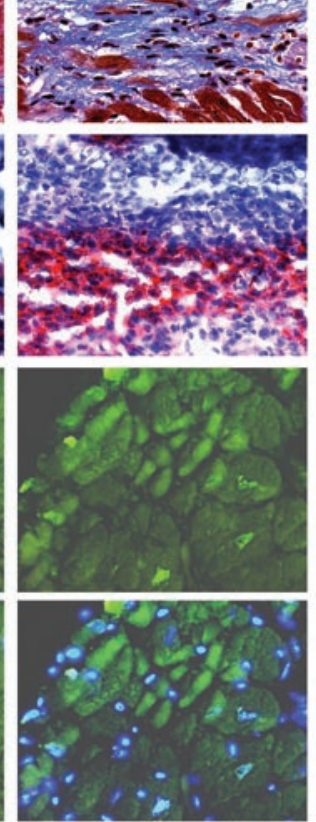

Figure 6

Morphological and histological phenotype. (A) Thin sections of the heart in $\mathrm{DP}^{+/+}, \mathrm{DP}^{+/-}$, and $\mathrm{DP}^{-/-}$mice stained with Masson Trichrome, showing ventricular dilatation and fibrosis in $\mathrm{DP}^{+/-}$and $\mathrm{DP}^{-/-}$mice. (B) H\&E-stained thin myocardial sections showing myocyte dropout and areas of excess interstitial tissue that comprise cells with adipocytic appearance in the $\mathrm{DP}^{-1-}$ mice. (C) Masson Trichrome-stained thin myocardial sections showing extensive areas of fibroadipocytic replacement of myocytes in DP-deficient mice, more prominent in $\mathrm{DP}^{-/-}$mice. (D) Oil Red O-stained thin myocardial sections showing accumulation of fat and adipocytes in $\mathrm{DP}^{+/-}$and $\mathrm{DP}^{-/-}$mice. (E) TUNEL-stained thin myocardial sections showing increased DNA nicking in DP-deficient mice. (F) Same panels as in E overlaid with DAPI-stained nuclei.

tance ( $\sim 5 \%$ observed versus $25 \%$ expected). The latter indicated a high rate of embryonic lethality, a finding that is in accord with the observed early embryonic lethality in germline (systemic) DP-null mice (17). Cardiac-restricted $\mathrm{DP}^{-/-}$embryos exhibited growth arrest at embryonic age E10-E12, appeared very pale, had no circulating red blood cells in organs, and were approximately $50 \%$ smaller than the $\mathrm{DP}^{+/-}\left(\mathrm{DP}^{+/-}\right.$plus $\alpha$-MHC-Cre $)$ and WT embryos when compared at day E15.5 (Supplemental Figure 2). $\mathrm{H} \& \mathrm{E}$ staining of thin sections of the whole-mount $\mathrm{DP}^{-/-}$embryos

showed poorly formed hearts with no chamber specification and unorganized cardiac myocytes. In addition, red blood cells were localized to the pericardial sac instead of cardiac chambers (i.e., not formed). Moreover, an excess number of cells resembling adipocytes, dispersed between myocytes and localized to adjacent areas, were also detected. Cardiac phenotype was normal in $\mathrm{DP}^{+/+}$ as well as $\mathrm{DP}^{+/-}$embryos with and without $\alpha-\mathrm{MHC}-\mathrm{Cre}$ transgene (Supplemental Figure 2).

Postnatal survival. The $\mathrm{DP}^{-/-}$mice surviving the embryonic period died predominantly within the first 2 weeks of the postnatal period, with the longest survival being 6 weeks. The $\mathrm{DP}^{+/-}$mice developed normally during the embryonic period. However, they exhibited an age-dependent penetrance of cardiac phenotype, including an approximately $20 \%$ incidence of premature death within the first 6 months after birth. The Kaplan-Meier survival plots for the WT, $\mathrm{DP}^{+/-}$, and $\mathrm{DP}^{-/-}$mice are depicted in Supplemental Figure 3.

Nuclear localization of PG in DP-deficient mice. To determine whether PG was translocated into the nucleus in cardiacrestricted DP-deficient mice, myocardial protein subfractions were blotted and probed with anti-PG antibody. The results were notable for the decreased expression level of PG in the cytosolic component in DP-deficient mice compared with WT mice (Figure 5A). In contrast, levels of PG protein in the nuclear subfraction were increased significantly.

Suppressed Wnt signaling and transcriptional switch to adipogenesis. Expression levels of c-myc and cyclin D1, targets genes of canonical Wnt/ $\beta$-catenin signaling, were decreased in the hearts of DP-deficient mice (Figure 5B). In contrast, expression levels of adipogenic genes C/EBP- $\alpha$ and adiponectin were increased (Figure 5B).

Fibroadipocytic replacement of myocytes in DP-deficient adult mice. Macroscopic phenotype was remarkable for grossly enlarged cardiac chambers in $\mathrm{DP}^{+/-}$and $\mathrm{DP}^{-/-}$mice and increased heart weight (Figure 6A). The right and left ventricles were both enlarged, without a discernible predilection toward involvement of the right ventricle. Microscopic phenotype of thin myocardial sections was remarkable for poorly organized myocytes with large areas of patchy fibrosis, the latter comprising up to one-third of the myocardium in $\mathrm{DP}^{-/-}$mice (Figure $6, \mathrm{~B}$ and $\mathrm{C}$ ). Oil Red O staining of thin myocardial sections showed excess accumulation of fat droplets in $\mathrm{DP}^{+/-}$and $\mathrm{DP}^{-/-}$mice, predominantly at the site of fibrosis (Figure 6D).

Increased apoptosis in DP-deficient mice. Apoptosis, as detected by TUNEL-positive cells, comprised $2.62 \% \pm 2.7 \%$ of the cardiac cells in $\mathrm{DP}^{-/-}$mice (with predominant localization to areas of fibrosis), less than $1 \%$ of the cardiac cells in $\mathrm{DP}^{+/-}$ mice, and less than $0.01 \%$ of the cells in WT mice $(P<0.001$; Figure 6E). No significant DNA laddering was detected, and expression levels of the p19 kDa fragment of caspase 3 were not significantly different among the groups (data not shown). Thus the increased number of TUNEL-positive cells in the absence of DNA laddering or increased expression level of the p19 fragment of caspase 3 suggests a relatively low level of apoptosis in DP-deficient mice.

Cardiac enlargement and dysfunction in DP-deficient mice. The heart weight-to-body weight ratio was the highest in the homozygous mutants and lowest in the WT mice $\left(\mathrm{DP}^{-/-}, 11.84 \pm 3.59\right.$; $\mathrm{DP}^{+/}$, 
Table 1

Echocardiographic indices of cardiac size and function

$\begin{array}{lccc} & & & \\ & \text { DP+/+ }^{+/+} & \text {DP+- } & P \\ n & 6 & 9 & \text { NA } \\ \text { Gender (M/F) } & 1 / 5 & 2 / 7 & 0.790^{\mathrm{A}} \\ \text { Age (mo) } & 6.3 \pm 0.14 & 6.3 \pm 0.25 & 0.927^{\mathrm{A}} \\ \text { Body weight (g) } & 29.4 \pm 3.2 & 28.8 \pm 2.0 & 0.697^{\mathrm{A}} \\ \text { Heart rate (bpm) } & 420 \pm 82 & 421 \pm 68 & 0.968^{\mathrm{A}} \\ \text { IVST (mm) } & 1.05 \pm 0.07 & 0.86 \pm 0.05 & <0.001^{\mathrm{A}} \\ \text { PWT (mm) } & 0.96 \pm 0.07 & 0.88 \pm 0.05 & 0.038^{\mathrm{B}} \\ \text { LVEDD (mm) } & 2.88 \pm 0.27 & 3.50 \pm 0.25 & 0.001^{\mathrm{A}} \\ \text { LVESD (mm) } & 1.04 \pm 0.25 & 1.89 \pm 0.55 & 0.007^{\mathrm{B}} \\ \text { LVFS (\%) } & 64.6 \pm 13.1 & 44.47 \pm 6.0 & 0.010^{\mathrm{B}} \\ \text { Vcf (c/s) } & 9.3 \pm 0.06 & 6.1 \pm 0.03 & 0.015^{\mathrm{B}} \\ \text { E/A } & 1.24 \pm 0.23 & 1.45 \pm 0.55 & 0.564^{\mathrm{B}} \\ & & & \end{array}$

IVST, interventricular septal thickness; PWT, posterior wall thickness; LVEDD, left ventricular end-diastolic dimension; LVESD, left ventricular end-systolic dimension; LVFS, left ventricular fractional shortening; Vcf, velocity of circumferential fiber shortening; c/s, circumference/second; $E / A$, ratio of early to late mitral inflow velocity. ${ }^{A} P$ values were determined by 2 -tailed Student's $t$ test. ${ }^{B} P$ values were determined by Kruskal-Wallis test.

$6.81 \pm 1.61 ; \mathrm{DP}^{+/+}, 4.85 \pm 0.56 ; P=0.004$; Supplemental Figure 4) M-mode, 2-dimensional, and Doppler echocardiography were performed in 6-month-old $\mathrm{DP}^{+/-}$and $\mathrm{DP}^{+/+}$mice. Because of high embryonic and early postnatal lethality, we could not establish a sufficient number of adult DP-/- mice for echocardiographic or electrophysiological studies. The results in $\mathrm{WT}$ and $\mathrm{DP}^{+/-}$mice, summarized in Table 1, are notable for thin ventricular walls, increased left ventricular end-diastolic and end-systolic diameters and reduced left ventricular ejection fraction. A representative $\mathrm{M}$-mode echocardiogram is shown in Figure 7A.

Spontaneous and induced ventricular arrbythmias in DP-deficient mice. Baseline resting electrocardiograms ( $n=5$ per group) showed spontaneous ventricular ectopic beats, ventricular couplets, and 3-beat ventricular tachycardia in $\mathrm{DP}^{+/-}$mice. In contrast, no ventricular arrhythmia was detected in WT mice. Otherwise, no significant differences in the baseline surface electrocardiographic parameters between WT and $\mathrm{DP}^{+/}$mice were detected (Supplemental Table 2). Upon application of a single ventricular electric extra stimulus, 4 of $5 \mathrm{DP}^{+/-}$mice developed ventricular arrhythmias, including runs of nonsustained polymorphic ventricular tachycardia (Figure 7B).

\section{Discussion}

Based on structural and functional similarities between PG, responsible for human ARVC (18), and $\beta$-catenin, the signal transducer of the canonical Wnt signaling pathway through Tcf/Lef1 transcrip-

\section{Figure 7}

Cardiac dysfunction and ventricular arrhythmias. (A) M-mode section of the left ventricle in $\mathrm{DP}^{+/+}$and $\mathrm{DP}^{+/-}$mice, showing left ventricular dilatation and reduced fractional shortening in $\mathrm{DP}^{+/-}$mice. (B) Instantaneous ECG and intracardiac electrograms in a heterozygous DPdeficient mouse. The tracings demonstrate an episode of polymorphic ventricular tachycardia induced by a ventricular premature extra stimulus following a ventricular fixed stimulation drive train. RA, right atrial electrogram; RV, right ventricular electrogram. I, II, and III are limb leads I, II, and III on surface ECG. tion factors (13), we developed a hypothesis and tested it through a series of in vitro and in vivo studies. We found that suppression of expression of DP, responsible for human ARVC (2) in cultured atrial myocytes and in mouse hearts, led to nuclear localization of PG and suppression of canonical Wnt/ $\beta$-catenin-Tcf/Lef1 signaling. The latter, a key regulator of transcriptional switch from myogenesis to adipogenesis (14), leads to enhanced adipogenesis, fibrogenesis, and myocyte apoptosis, the phenotype of human ARVC (1). We also showed DP was essential for cardiac embryogenesis and embryo survival, as was also shown in systemic deletion of DP (17). Furthermore, we show DP-deficient hemizygous mice recapitulated the phenotype of human ARVC by exhibiting fibroadipocytic replacement of myocytes, enhanced myocyte apoptosis, ventricular dysfunction, and ventricular arrhythmias. Collectively, the results provide for what we believe to be the first molecular mechanism for the pathogenesis of ARVC, a major cause of SCD and heart failure in humans (1) and establish cardiac-restricted $\mathrm{DP}^{+/-}$mice as what we believe to be the first mouse model for human ARVC.

The tenet of the proposed hypothesis and the basis for fibroadipocytic replacement of myocytes is suppression of canonical Wnt/ $\beta$-catenin signaling through Tcf/Lef1 transcription factors. The results of in vitro TOP-flash assay, a robust and well-established quantitative technique to determine $\beta$-catenin-Tcf/Lef-mediated gene transcription (19), provide direct evidence in support of the hypothesis. Similarly, reduced expression levels of mRNAs for selected downstream target genes of canonical Wnt signaling, increased expression levels of transcriptional regulators of adipogenesis and lipid genes, and accumulation of fat droplets in DPdeficient HL-1 cells and mice hearts provide further evidence in support of the hypothesis. The findings are also in accord with the existing literature implicating canonical $\mathrm{Wnt} / \beta$-catenin signaling as a major switch regulator of adipogenesis versus myogenesis (14, $20,21)$. Accordingly, inhibition or suppression of Wnt/ $\beta$-catenin signaling by overexpression of axin or a dominant-negative Tcf7l2

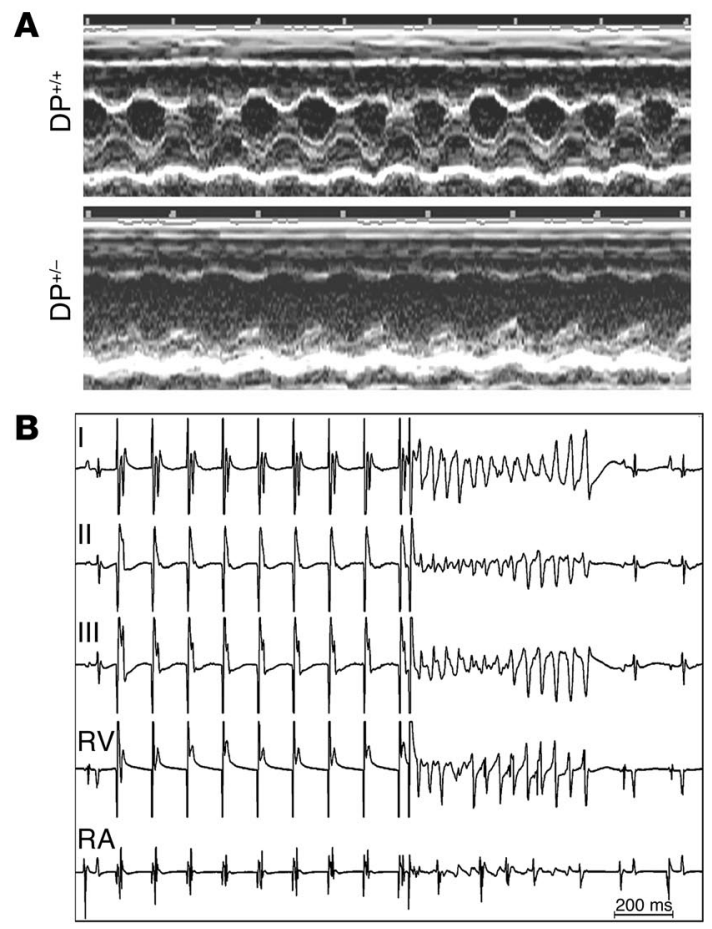


switches on adipogenesis and leads to proliferation of adipocytes (14). In contrast, activation of canonical Wnt/ $\beta$-catenin signaling enhances myogenesis, inhibits adipogenic transcription factors $\mathrm{C} / \mathrm{EBP}-\alpha$ and PPAR $\gamma$, and maintains preadipocytes in an undifferentiated state $(14,20-22)$. The plausibility of suppressed Wnt signaling as a mechanism for the pathogenesis of ARVC is further strengthened by the evidence for increased myocyte apoptosis in DP-deficient mice, a feature of human ARVC, and the known protective role of Wnt signaling against apoptosis (15, 23-25). Activation of Wnt signaling blocks apoptosis in a variety of cells, including 3T3-L1 preadipocytes (15). In contrast, suppression of Wnt signaling provokes apoptosis (15), which we also illustrated in cardiac-restricted DP-deficient mice. Thus the collective data establishes suppression of canonical Wnt signaling, caused by competitive interactions between PG and $\beta$-catenin (12), as a molecular mechanism for the fibroadipocytic replacement of myocytes and enhanced myocyte apoptosis in ARVC. The results in the mouse and cell culture models, while direct and robust, will require complimentary studies in human patients with ARVC.

Molecular genetic studies suggest ARVC is a disease of desmosomal proteins (reviewed in ref. 2). Desmosomes are complex intercellular junctions responsible for cell-cell adhesion (reviewed in ref. 26). They are particularly abundant in cardiac myocytes and epidermal cells (26). Interactions among multiple proteins at multiple domains are necessary to form desmosomes and maintain their integrity. DP, a member of plakin family, PG, an armadillo repeat protein, and PKP2, a member of plakin family, are essential for desmosome assembly and embryonic development $(17,27,28)$. Systemic null mutations in DP, PG, and PKP2 lead to embryonic lethality at E6.5, E9.5, and E12-E14, respectively $(17,27,28)$. Systemic deletion of DP leads to growth retardation, collapse of keratin network, impaired desmosome assembly, disrupted cell-cell attachment, and embryonic lethality at E6.5 in homozygous embryos (17). The heterozygous embryos and newborn mice did not show a discernible phenotype. However, they were not examined at a later time point. The phenotype in mice with germline deletion of $\mathrm{PG}\left(\mathrm{PG}^{-/-}\right)$is remarkable for embryonic lethality at E10.5 onward, due to severe cardiac defects (29). Surviving mutant mice die around birth, presumably due to heart failure, skin blistering, and subcorneal acantholysis. Heart fibers isolated from $\mathrm{PG}^{-/-}$embryonic mice show reduced compliance, especially at lower fiber extension levels, while the contractile parameters were apparently unchanged (30). Thus it was not surprising that cardiac-restricted homozygous deletion of DP also led to a very high rate of embryonic lethality, which occurred between E10.5 and E15.5, a time consistent with conditional expression regulated by the $\alpha$-MHC promoter. We did not study the desmosome structure and formation in DPdeficient hearts, as previous studies in systemic $\mathrm{DP}^{-/-}$mice have established the essential role of DP in desmosome assembly in the heart and elsewhere (17). Thus, poor desmosome assembly is expected in cardiac-restricted DP-deficient mice.

PG (also known as $\gamma$-catenin) and $\beta$-catenin are two closely related armadillo repeat proteins with a high degree of sequence identity and homology (12). PG and $\beta$-catenin could interact at multiple levels including nuclear localization, binding to Tcf/Lef transcription factors, ubiquitination, phosphorylation, binding to axin and adenomatous polyposis coli, incorporation into the adherens junction, and desmosomal assembly. The functional and phenotypic consequences of these interactions are complex but in general antagonistic (12). PG and $\beta$-catenin bind to different sites on the Tcf7l2 (formerly known as Tcf-4) transcription factor and impart contrasting effects (31-33). The PG-containing Tcf712/Lef1 transcription factor complex binds to DNA less efficiently than does the $\beta$-catenin-containing Tcf7l2/Lef1 complex (31). Additional studies will be required to delineate specific interactions between PG and $\beta$-catenin that lead to suppression of canonical Wnt $/ \beta$-catenin signaling in ARVC.

The pathogenesis of ARVC described in our studies is based on the essential role of the $\mathrm{Wnt} / \beta$-catenin signaling in regulating the transcriptional switch between myogenesis versus adipogenesis $(14,20,21)$. We have not identified the cell source of excess adipocytes in the heart, but it is likely to be composed of cardiac myoblasts or resident and circulating mesenchymal stems cells, which in the absence of Wnt signaling could preferentially differentiate into adipocytes (14). An alternative source of adipocytes is fibrocytes, which are considered adipocyte progenitor cells (34). The latter possibility is supported by the predominant colocalization of adipocytes and fibrosis in the myocardium of patients with ARVC and in the hearts of DP-deficient mice, as observed in the present study. We also noted that expression and nuclear localization of PPAR $\gamma$ was restricted to fibrotic areas in DP-deficient mouse hearts, suggesting a possible origin of adipocytes from fibrocytes or prefibroblasts (data not shown). In vivo cell fate mapping experiments will be required to establish the cell source of adipocytes in ARVC. We also note that while our data emphasizes suppressed Wnt signaling as a mechanism for the pathogenesis of ARVC, it does not exclude the possible involvement of additional transcriptional regulators of adipogenesis, such as Rho family of small GTPases and GATA transcription factors, in the pathogenesis of $\operatorname{ARVC}(35,36)$. Rho family of small GTPases is considered a master switch regulator of adipogenesis versus cardiogenesis (36), while GATA transcription factors regulate terminal differentiation of preadipocytes to adipocytes (35). In view of considerable interactions between Wht signaling and small GTPases, direct or indirect involvement of other transcriptional regulators of adipogenesis in the pathogenesis of the ARVC phenotype would merit further investigation (37). Finally, while cardiac-restricted DP-deficient mice showed a several-fold increase in the number of TUNEL-positive cells in the heart, there was no significant difference in the number of apoptotic cells between stably transfected DP-deficient and DP-competent HL-1 cells. The latter could reflect selection against proapoptotic cells during the stable transfection procedure, slower rate of proliferation of DP-deficient cells, and the presence of SV40 large T-antigen in HL-1 cells, which possesses antiapoptotic activity (38).

The lack of an appropriate genetically defined animal model and the paucity of mechanistic data have hampered our understanding of the molecular pathogenesis of ARVC disease and development of new diagnostic markers and therapeutic targets. Naturally occurring ARVC has been described in Boxer dogs (39). However, the model suffers from an undefined genetic basis. Recently, a mouse model was described in which transcription of an intronic retroposon in laminin receptor 1 led a phenotype resembling right ventricular dysplasia (40). Detailed examination showed a distinct phenotype characterized by epicardial fibrosis and, more importantly, the absence of adipocytic infiltration of myocardium and ventricular arrhythmias (40). Hence, the model probably represents a distinct phenotype and not 
true ARVC. Finally, a mouse model of catecholaminergic polymorphic ventricular tachycardia has been developed through conditional expression of a mutant ryanodine receptor in the heart (41). The model does not exhibit histological phenotype of ARVC and is a distinct phenotype (41). Thus cardiac-restricted DP-deficient mice provide for a genetically defined animal model of ARVC that could prove essential for further elucidating the molecular pathogenesis of ARVC and identification of novel diagnostic markers and therapeutic targets.

In summary, through a series of in vitro and in vivo studies we have delineated what we believe to be a novel molecular mechanism for the pathogenesis of ARVC and have established cardiac-restricted DP-deficient mice as a model that recapitulates the phenotype of human ARVC. The findings have the potential to provide for a unifying mechanism for the pathogenesis of adipocytic replacement of myocytes in all forms of ARVC and the opportunity to identify new diagnostic markers and therapeutic targets.

\section{Methods}

siRNA constructs. The 21-nucleotide-long inverted repeats, separated by a 6-nucleotide linker, were inserted downstream of the U6 promoter of pSilencer 2.1-U6 neo (Ambion). Six thymidines were inserted downstream of the antisense strand to provide a stop signal for the polymerase III RNA polymerase. The sense strands of the hairpin RNAs were homologous to a 21-nucleotide region in the Dsp mRNA starting either at nucleotide 799 (siRNA DP-799) or at nucleotide 1102 (siRNA DP-1102). Sequences of siRNAs are provided in Supplemental Table 1.

Cell culture and stable transfections. HL-1 cardiac myocytes were maintained as previously reported (42). Briefly, HL-1 cells were grown in Claycomb medium (Sigma-Aldrich) supplemented with $10 \%$ fetal bovine serum (Sigma-Aldrich), $0.1 \mathrm{mM}$ norepinephrine (Sigma-Aldrich), $2 \mathrm{mM}$ L-glutamine (Sigma-Aldrich), and penicillin/streptomycin/amphotericin B combination (Invitrogen) in a humidified $5 \% \mathrm{CO}_{2}$ incubator at $37^{\circ} \mathrm{C}$. After several passages, cells were transfected with $1 \mu \mathrm{g}$ of plasmid DNA per plate, $8 \mu \mathrm{l}$ of enhancer reagent, and $25 \mu \mathrm{l}$ of effectene reagent (QIAGEN). On the second day after transfection, fresh growth media supplemented with $50 \mathrm{mg} / \mathrm{ml}$ Geneticin (Invitrogen) as the selection agent was added. The selection was allowed to proceed for 14 days, and the selected colonies were harvested and maintained in the selection media.

Upon establishment of stable cell lines, each set of subsequent experiments was performed in triplicate in 35- $\mathrm{mm}$ plates and was repeated 3-6 times. The number of cells in each $35-\mathrm{mm}$ plate was approximately $5 \times 10^{4}$ cells/well. The observer was not blinded to the experimental group.

Genetically engineered mice. The Animal Subjects Committee of Baylor College of Medicine approved the experiments. Cardiac-restricted DPdeficient mice were generated by crossing mice in which the second exon of $D s p$ gene is flanked by loxP sequence (floxed DP mice) with mice expressing Cre recombinase under the control of the $\alpha$-MHC promoter ( $\alpha$-MHC-Cre mice). The floxed DP mice (129/SvJ strain) were described previously and were kindly provided by E. Fuchs (Rockefeller University, New York, New York, USA) (43). The $\alpha$-MHC-Cre mouse line (FVB/N strain) was as described previously (44). Sequences of the oligonucleotide primers used in PCR reactions are provided in Supplemental Table 1.

Mouse genotyping. Mice were genotyped by PCR of tail DNA using oligonucleotide primers flanking exon 2 (the floxed exon) of $D s p$ gene. Excision of exon 2 by Cre recombinase in the heart was analyzed by Southern blotting of DNA extracted from the heart. Southern blotting was performed following digestion of genomic DNA extracted from the heart with BamH1 restriction endonuclease, agarose gel electrophoresis, and transfer to a nylon membrane. Hybridization was performed in ExpressHyb hybridiza- tion solution (BD Biosciences - Clontech) per the manufacturer's protocol at $65^{\circ} \mathrm{C}$. The probe was generated by PCR amplification of a 332-bp fragment encompassing the exon 2 of Dsp gene (Supplemental Table 1).

The presence of the $\alpha$-MHC-Cre transgene was determined by PCR (Supplemental Table 1) as described previously (44).

Embryo analysis. Embryos were harvested systematically at days E10.5, E12.5, E14.5, E15.5, and E18.5. Embryos were genotyped by PCR using DNA extracted from the amniotic sac (Supplemental Table 1).

Induction of lipid accumulation. Adipogenesis was induced as described previously (14). Briefly, confluent control and DP-deficient cells were treated with the selection media supplemented with $5 \mathrm{mg} / \mathrm{ml}$ insulin (SigmaAldrich), $0.5 \mathrm{mM}$ 3-isobutyl-1-methylxanthine (Sigma-Aldrich), and $1 \mathrm{mM}$ dexamethasone (Sigma-Aldrich) for 3 days. The media was changed to selection media supplemented with $5 \mathrm{mg} / \mathrm{ml}$ insulin, and fresh selection media supplemented with $5 \mathrm{mg} / \mathrm{ml}$ insulin was added every other day. Fifteen days after the confluence, cells were stained with Oil Red O (see below) to visualize accumulated fat droplets.

Histology and detection of fat accumulation. Myocardial architecture was examined by $\mathrm{H} \& \mathrm{E}$, and fibrosis by Masson Trichrome staining of thin myocardial sections, as described previously $(45,46)$. Fat accumulation was detected by Oil Red O staining of thin myocardial sections or cultured cells. For Oil Red O staining, cells and were washed twice with PBS and then fixed with $10 \%$ formalin in PBS for 2 hours at $37^{\circ} \mathrm{C}$. Following washing 3 times with water, $3 \mathrm{ml}$ of dye solution $(0.42 \%$ [wt/vol] Oil Red O; Sigma-Aldrich) in isopropanol was added to each plate. Cells were incubated 3 hours at $37^{\circ} \mathrm{C}$, excess dye was removed, and cells were washed once with PBS and then air dried for 10 minutes.

For Oil Red O staining of tissue, $10-\mu \mathrm{m}$-thick freshly frozen myocardial sections were fixed in $10 \%$ neutral buffered formalin, washed with distilled water, and placed in $100 \%$ propylene glycol for 2 minutes. Slides were then placed in Oil Red O solution for 1 hour at $60^{\circ} \mathrm{C}$, rinsed with distilled water, and counterstained with modified Mayer's hematoxylin.

Detection of apoptosis. Apoptosis was detected by 3 complimentary techniques of agarose gel electrophoresis to detect DNA laddering, TUNEL assay, and immunoblotting to detect expression of truncated caspase 3 , as previously described (45).

Immunoblotting. Immunoblotting was performed as described previously (45). In brief, heart tissues and cells were frozen in liquid nitrogen and homogenized with $0.5 \mathrm{ml}$ of lysis buffer (20 mM Tris-HCl, pH 8.0; $0.15 \mathrm{M}$ $\mathrm{NaCl}$; $1 \%$ Triton X-100; 0.5\% NP-40; 1 mM EDTA; and complete protease inhibitors cocktail; Roche). Protein concentration was determined with the Bradford protein assay (Bio-Rad). Aliquots of $30 \mu \mathrm{g}$ of protein extracts were separated on SDS-polyacrylamide gels and transferred to nitrocellulose membranes. Membranes were probed with a rabbit polyclonal antibody against PG (1:400 dilution, sc-7900; Santa Cruz Biotechnology Inc.), rabbit polyclonal antibody against DP (1:200 dilution, AHP320; Serotec), rabbit polyclonal antibody against PPAR $\gamma$ (1:400 dilution, sc-7196; Santa Cruz Biotechnology Inc.), mouse monoclonal antibody against $\beta$-catenin (1:1,000 dilution, C-7082; Sigma-Aldrich), and rabbit monoclonal antibody against caspase-3 (1:1,000 dilution, 8G10; Cell Signaling Technology).

The secondary antibody against mouse primary antibodies was goat anti-mouse IgG-HRP (1:2,000 dilution, sc-2005; Santa Cruz Biotechnology Inc.); against rabbit primary antibodies, the secondary antibody was donkey anti-rabbit IgG-HRP (1:2,000 dilution, sc-2313; Santa Cruz Biotechnology Inc.).

Immunofluorescence. Cells grown on glass coverslips were fixed in $4 \%$ paraformaldehyde, incubated with PBS containing $100 \mathrm{mmol} / \mathrm{l}$ glycine, and washed with PBS. Cells were permeabilized in PBS containing $0.1 \%$ Triton X-100, blocked with $5 \%$ albumin for 1 hour, and incubated with the primary antibodies overnight. 
After several rounds of washing, fluorescence-labeled secondary antibodies were added for 1 hour, and the coverslips were washed and mounted using Fluorescence Mounting Medium (Biomeda). Samples were analyzed under epifluorescence microscopy. Immunofluorescence staining of thin myocardial sections was performed as previously described (45).

The primary antibodies were as described for immunoblotting, and the secondary antibodies were goat anti-mouse-fluorescein (catalog no. 31542; Pierce Biotechnology) and goat anti-rabbit-rhodamine (catalog no. AP132R; Chemicon International), both at 1:2,000 dilution.

RNA isolation and RT-PCR. Total RNA was isolated from HL-1 cells with TRIzoL (Invitrogen). Aliquots of $2 \mu \mathrm{g}$ of total RNA extracts were reverse transcribed into cDNA with SuperScript II (Invitrogen) following the manufacturer's instructions. The RT products were then diluted to a final volume of $200 \mu \mathrm{l}$ with water and amplified by PCR using $1 \mu \mathrm{l}$ of each RT product in a 20- $\mu \mathrm{l}$ PCR reaction in the presence of ${ }^{32} \mathrm{P}-\mathrm{dCTP}$ (Supplemental Table 1).

TOP-flash assay. The Tcf/Lef reporter plasmid, TOP-flash, and its mutant control, FOP-flash, were purchased from Upstate USA Inc. In brief, cells were cotransfected with $2 \mu \mathrm{g}$ of reported construct pTOP-flash, which contains consensus sequence of Tcf/Lef enhancer upstream of the luciferase enzyme coding region, or pFOP-flash (control). To serve as internal control for transfection, cells were cotransfected with a non-Tcf/Lef-dependent $\beta$-gal coding vector. Luciferase and $\beta$-gal activities were measured 48 hours after transfection. Vector alone was included in the experiments. Experiments were performed in triplicate and repeated at least 3 times. Tcf-mediated gene transcription was determined by the ratio of pTOP-flash/pFOPflash luciferase activity, each normalized to $\beta$-gal enzymatic activity levels. The mean values of the normalized ratios were compared.

M-mode, 2-dimensional, and Doppler echocardiography. Echocardiography was performed as described previously using a dedicated HP Sonos 5500 System, equipped with a $15 \mathrm{MHz}$ linear transducers, with the exception of using minimal sedation $(47,48)$. Indices of cardiac size and function including Doppler indices were measured and analyzed. Wall thickness and dimensions were measured from $\mathrm{M}$-mode images using the leading-edge method on 3 consecutive cardiac cycles. Ventricular fractional shortening, ejection fraction, ejection time, and circumferential velocity of shortening were calculated as previously described $(47,48)$.

Electrophysiology studies. Mice were anesthetized by intraperitoneal injection $(15 \mathrm{ml} / \mathrm{kg})$ of a mixture of sodium pentobarbital $(4.13 \mathrm{mg} / \mathrm{ml})$, sodium chloride $(6.61 \mathrm{mg} / \mathrm{ml})$, and $0.18 \mathrm{ml} \mathrm{30 \%} \mathrm{ethanol} / \mathrm{ml}$. Six ECG limb leads were continuously recorded during electrophysiology study (CardioLab; GE Healthcare). Meanwhile, a catheter carrying 8 electrodes (2 F, model CIBer;
NuMED) was inserted through the jugular vein and advanced into the right atrium and ventricle for electrical stimulation and recording. Electrophysiology studies, similar to standard clinical methods, were performed as previously described for mice (49). Electrical stimulation was applied through the catheter electrodes using an external stimulator (model S8800; AstroMed Inc.). After a period of baseline rhythm, decremental atrial pacing was applied to determine sinus node recovery time as well as atrioventricular nodal conduction properties including Wenckebach and 2:1 atrioventricular conduction. Subsequently, refractory periods were determined by delivering a drive train (S1) followed by a progressively premature extra stimulus (S2). The effective refractory period was defined as the longest S1-S2 coupling interval that failed to generate a propagated beat with S2 in 2 separate attempts. Inducibility of atrial and ventricular arrhythmias was assessed in all mice by delivering 2 extra stimuli (S2, S3) that were programmed at progressively shorter intervals following a drive train (S1).

Statistics. Statistical analysis was performed using STATA-Intercooled version 9.1 software and was primarily similar to previously described analyses $(45,48)$. Kaplan-Meier survival curves were constructed, and the total survival rates were compared among the 3 study groups $\left(\mathrm{DP}^{+/+}, \mathrm{DP}^{+/-}\right.$, and $\mathrm{DP}^{-/-}$) by log-rank test. The number of TUNEL-positive cells, extent of fibrosis, and echocardiographic indices of cardiac size and function and wall thickness were analyzed for the homogeneity of the variances and normality assumptions among the 3 experiment groups by Bartlett's test. Differences in variables were compared by ANOVA if they were normally distributed and by the nonparametric Kruskal-Wallis test for variables that violated normality assumption. Pairwise comparisons were performed by Tukey's test. $P$ values less than 0.05 were considered statistically significant.

\section{Acknowledgments}

This work was supported by grants from the National Heart, Lung, and Blood Institute (R01-HL68884), Specialized Centers of Research (P50-HL42267), Greater Houston Community Foundation (TexGen), and the Methodist Hospital Research Institute.

Received for publication December 22, 2005, and accepted in revised form April 4, 2006.

Address correspondence to: A.J. Marian, Section of Cardiology, Baylor College of Medicine, One Baylor Plaza, 519D, Houston, Texas 77030, USA. Phone: (713) 798-7454; Fax: (713) 790-3147; E-mail: amarian@bcm.tmc.edu.
1. Corrado, D., et al. 1997. Spectrum of clinicopathologic manifestations of arrhythmogenic right ventricular cardiomyopathy/dysplasia: a multicenter study. J. Am. Coll. Cardiol. 30:1512-1520.

2. Sen-Chowdhry, S., Syrris, P., and McKenna, W.J. 2005. Genetics of right ventricular cardiomyopathy. J. Cardiovasc. Electrophysiol. 16:927-935.

3. Maron, B.J., et al. 1996. Sudden death in young competitive athletes. Clinical, demographic, and pathological profiles. JAMA. 276:199-204.

4. Tabib, A., et al. 2003. Circumstances of death and gross and microscopic observations in a series of 200 cases of sudden death associated with arrhythmogenic right ventricular cardiomyopathy and/or dysplasia. Circulation. 108:3000-3005.

5. Kaplan, S.R., et al. 2004. Structural and molecular pathology of the heart in Carvajal syndrome. Cardiovasc. Pathol. 13:26-32.

6. Norman, M., et al. 2005. Novel mutation in desmoplakin causes arrhythmogenic left ventricular cardiomyopathy. Circulation. 112:636-642.

7. Protonotarios, N., et al. 1986. Cardiac abnormalities in familial palmoplantar keratosis. Br. Heart J. 56:321-326
8. Pilichou, K., et al. 2006. Mutations in desmoglein-2 gene are associated with arrhythmogenic right ventricular cardiomyopathy. Circulation. 113:1171-1179.

9. Zhurinsky, J., Shtutman, M., and Ben Ze'ev, A. 2000 Differential mechanisms of LEF/TCF family-dependent transcriptional activation by beta-catenin and plakoglobin. Mol.Cell. Biol. 20:4238-4252.

10. Klymkowsky, M.W., Williams, B.O., Barish, G.D., Varmus, H.E., and Vourgourakis, Y.E. 1999. Membrane-anchored plakoglobins have multiple mechanisms of action in Wnt signaling. Mol. Biol. Cell. 10:3151-3169.

11. Ben Ze'ev, A., and Geiger, B. 1998. Differential molecular interactions of beta-catenin and plakoglobin in adhesion, signaling and cancer. Curr. Opin. Cell Biol. 10:629-639.

12. Maeda, O., et al. 2004. Plakoglobin (gammacatenin) has TCF/LEF family-dependent transcriptional activity in beta-catenin-deficient cell line. Oncogene. 23:964-972.

13. Moon, R.T., Bowerman, B., Boutros, M., and Perrimon, N. 2002. The promise and perils of Wnt signaling through beta-catenin. Science. 296:1644-1646.
14. Ross, S.E., et al. 2000. Inhibition of adipogenesis by Wnt signaling. Science. 289:950-953.

15. Longo, K.A., et al. 2002. Wnt signaling protects 3T3-L1 preadipocytes from apoptosis through induction of insulin-like growth factors. J. Biol. Chem. 277:38239-38244.

16. Chen, S., et al. 2001. Wnt-1 signaling inhibits apoptosis by activating beta-Catenin/T cell factor-mediated transcription. J. Cell Biol. 152:87-96.

17. Gallicano, G.I., et al. 1998. Desmoplakin is required early in development for assembly of desmosomes and cytoskeletal linkage. J. Cell Biol. 143:2009-2022.

18. McKoy, G., et al. 2000. Identification of a deletion in plakoglobin in arrhythmogenic right ventricular cardiomyopathy with palmoplantar keratoderma and woolly hair (Naxos disease). Lancet. 355:2119-2124.

19. You, L., et al. 2004. Inhibition of Wnt-2-mediated signaling induces programmed cell death in non-smallcell lung cancer cells. Oncogene. 23:6170-6174.

20. Polesskaya, A., Seale, P., and Rudnicki, M.A. 2003. Wnt signaling induces the myogenic specification of resident CD45+ adult stem cells during muscle 
regeneration. Cell. 113:841-852.

21. Chen, A.E., Ginty, D.D., and Fan, C.M. 2005. Protein kinase A signalling via CREB controls myogenesis induced by Wnt proteins. Nature. 433:317-322.

22. Liu, J., and Farmer, S.R. 2004. Regulating the balance between peroxisome proliferator-activated receptor gamma and beta-catenin signaling during adipogenesis: a glycogen synthase kinase-3 beta phosphorylation-defective mutant of beta-catenin expression of a subset of adipogenic genes. J. Biol. Chem. 279:45020-45027.

23. Runge, M.S., et al. 2000. Morphological patterns of death by myocytes in arrhythmogenic right ventricular dysplasia. Am. J. Med. Sci. 320:310-319.

24. Nishikawa, T., et al. 1999. Programmed cell death in the myocardium of arrhythmogenic right ventricular cardiomyopathy in children and adults. Cardiovasc. Pathol. 8:185-189.

25. Mallat, Z., et al. 1996. Evidence of apoptosis in arrhythmogenic right ventricular dysplasia. N. Engl. J. Med. 335:1190-1196.

26. Cheng, X., and Koch, P.J. 2004. In vivo function of desmosomes. J. Dermatol. 31:171-187.

27. Ruiz, P., et al. 1996. Targeted mutation of plakoglobin in mice reveals essential functions of desmosomes in the embryonic heart. J. Cell Biol. 135:215-225.

28. Grossmann, K.S., et al. 2004. Requirement of plakophilin 2 for heart morphogenesis and cardiac junction formation. J. Cell Biol. 167:149-160.

29. Bierkamp, C., Mclaughlin, K.J., Schwarz, H., Huber, O., and Kemler, R. 1996. Embryonic heart and skin defects in mice lacking plakoglobin. Dev. Biol. 180:780-785.

30. Isac, C.M., et al. 1999. Plakoglobin is essential for myocardial compliance but dispensable for myofibril insertion into adherens junctions. J. Cell. Biochem. 72:8-15.
31. Zhurinsky, J., Shtutman, M., and Ben Ze'ev, A. 2000. Differential mechanisms of LEF/TCF family-dependent transcriptional activation by beta-catenin and plakoglobin. Mol.Cell. Biol. 20:4238-4252.

32. Simcha, I., et al. 1998. Differential nuclear translocation and transactivation potential of beta-catenin and plakoglobin. J. Cell Biol. 141:1433-1448.

33. Miravet, S., et al. 2002. The transcriptional factor Tcf-4 contains different binding sites for beta-catenin and plakoglobin. J. Biol. Chem. 277:1884-1891.

34. Hong, K.M., Burdick, M.D., Phillips, R.J., Heber, D., and Strieter, R.M. 2005. Characterization of human fibrocytes as circulating adipocyte progenitors and the formation of human adipose tissue in SCID mice. FASEB J. 19:2029-2031.

35. Tong, Q., et al. 2000. Function of GATA transcription factors in preadipocyte-adipocyte transition. Science. 290:134-138.

36. Sordella, R., Jiang, W., Chen, G.C., Curto, M., and Settleman, J. 2003. Modulation of Rho GTPase signaling regulates a switch between adipogenesis and myogenesis. Cell. 113:147-158.

37. Esufali, S., and Bapat, B. 2004. Cross-talk between Rac1 GTPase and dysregulated Wnt signaling pathway leads to cellular redistribution of beta-catenin and TCF/LEF-mediated transcriptional activation. Oncogene. 23:8260-8271.

38. Tsai, S.C., et al. 2000. Simian virus 40 large T antigen binds a novel Bcl-2 homology domain 3-containing proapoptosis protein in the cytoplasm. J. Biol. Chem. 275:3239-3246.

39. Basso, C., et al. 2004. Arrhythmogenic right ventricular cardiomyopathy causing sudden cardiac death in boxer dogs: a new animal model of human disease. Circulation. 109:1180-1185.

40. Asano, Y., et al. 2004. Lamr1 functional retroposon causes right ventricular dysplasia in mice. Nat. Genet. 36:123-130.
41. Cerrone, M., et al. 2005. Bidirectional ventricular tachycardia and fibrillation elicited in a knock-in mouse model carrier of a mutation in the cardiac ryanodine receptor. Circ. Res. 96:e77-e82.

42. Claycomb, W.C., et al. 1998. HL-1 cells: a cardiac muscle cell line that contracts and retains phenotypic characteristics of the adult cardiomyocyte. Proc. Natl. Acad. Sci. U. S. A. 95:2979-2984.

43. Vasioukhin, V., Bowers, E., Bauer, C., Degenstein, L., and Fuchs, E. 2001. Desmoplakin is essential in epidermal sheet formation. Nat. Cell Biol. 3:1076-1085.

44. Agah, R., et al. 1997. Gene recombination in postmitotic cells. Targeted expression of Cre recombinase provokes cardiac-restricted, site-specific rearrangement in adult ventricular muscle in vivo. J. Clin. Invest. 100:169-179.

45. Senthil, V., et al. 2005. Prevention of cardiac hypertrophy by atorvastatin in a transgenic rabbit model of human hypertrophic cardiomyopathy. Circ. Res. 97:285-292.

46. Patel, R., et al. 2001. Simvastatin induces regression of cardiac hypertrophy and fibrosis and improves cardiac function in a transgenic rabbit model of human hypertrophic cardiomyopathy. Circulation. 104:317-324

47. Tsybouleva, N., et al. 2004. Aldosterone, through novel signaling proteins, is a fundamental molecular bridge between the genetic defect and the cardiac phenotype of hypertrophic cardiomyopathy. Circulation. 109:1284-1291.

48. Lutucuta, S., et al. 2004. Induction and reversal of cardiac phenotype of human hypertrophic cardiomyopathy mutation cardiac troponin T-Q92 in switch on-switch off bigenic mice. J. Am. Coll. Cardiol. 44:2221-2230.

49. Appleton, G.O., et al. 2004. Determinants of cardiac electrophysiological properties in mice. J. Interv. Card. Electrophysiol. 11:5-14. 